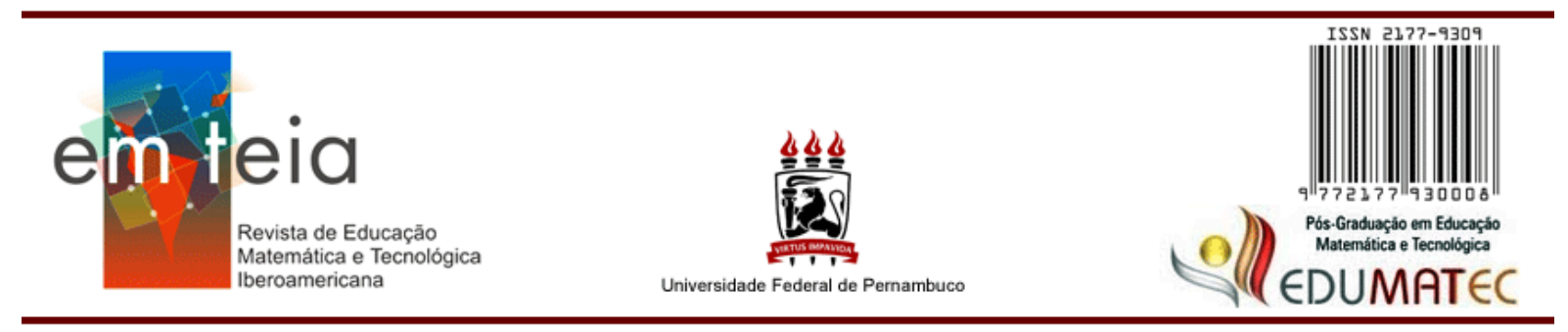

\title{
GEOMETRIA E DESENHO NO CONTEXTO DA REFORMA DA INSTRUÇÃO PRIMÁRIA DE MINAS GERAIS EM 1906
}

\section{Resumo}

\author{
Elenice de Souza Lodron Zuin \\ Doutora em Educação Matemática \\ PUC MINAS - Minas Gerais - Brasil \\ elenicezuin@gmail.com
}

Neste artigo, apresentamos os resultados de nosso estudo relativos ao ensino de Geometria e Desenho proposto na reforma do ensino primário do Estado de Minas Gerais em 1906, no período da Primeira República no Brasil. Verificamos que os programas, acompanhados das instruções metodológicas, traziam orientações claramente calcadas no ensino intuitivo, demonstrando uma tentativa de se incorporar novas formas de ensino e aprendizagem na educação elementar.

Palavras-Chave: Ensino Primário. Geometria. Desenho. Minas Gerais. Primeira República.

\section{Geometría y Dibujo en el contexto de la reforma de la educación primaria de Minas Gerais en 1906}

\section{Resumen}

En ese artículo, tenemos como objetivo presentar los resultados de nuestro estudio relativo a la enseñanza de la Geometría y del Dibujo propuesta en la reforma de la escuela primaria en Minas Gerais en 1906, período de la Primera República en Brasil. Ha sido verificado que los programas y las instrucciones metodológicas tenían orientaciones claramente apoyadas en la educación intuitiva, demostrando un intento de insertar nuevas formas de enseñanza y aprendizaje en la educación elementar.

Palabras clave: Escuela primaria, Geometría, Dibujo, Minas Gerais, Primera República.

\section{INTRODUÇÃO}

Inaugurada em 12 de dezembro de 1897, a nova capital de Minas Gerais, Belo Horizonte, estava entre as primeiras cidades brasileiras planejadas. O espírito republicano circulava pela nova capital no dealbar do século XX. ${ }^{1}$ Havia também a aspiração de se modernizar na área da educação. Era imperativo formar os novos cidadãos e os novos trabalhadores do Novecentos.

\footnotetext{
${ }^{1}$ Ouro Preto foi capital de Minas Gerais até a fundação de Belo Horizonte, inaugurada em 12 dezembro de 1897.
} 
No Brasil, desde as últimas décadas do Oitocentos, havia a defesa por uma escola que colocasse o aluno no centro do processo educacional, se contrapondo aos métodos tradicionais. Dentro desse cenário, ocorre a reforma da instrução pública primária em Minas Gerais no ano de 1906, sob a égide da instauração de uma nova cultura escolar: outra forma de organização do tempo e espaço, criação de grupos escolares, graduação do ensino em séries, inserção de outros saberes e implementação de novas metodologias.

Nos palcos das discussões educacionais, nas últimas décadas do Oitocentos, Ruy Barbosa apontava algumas falhas do ensino:

... o que até hoje se distribue em nossas escolas de primeiras lettras, mal merece o nome de ensino. Tudo nellas é mechanico e esteril; a creança, em vez de ser o mais activo collaborador na sua própria instrucção, como exigem os cânones racionaes e scientíficos do ensino elementar, representa o papel de um recipiente passivo de formulas, definições e sentenças, embutidas na infância a poder de meios mais ou menos compressivos. O mestre e o compedio afirmam, o aluno repete com a fidelidade do automato; e o que hoje aprendeu, sem lhe deixar mossa mais que memória, amanhã dessaberá, sem vestígios, na intelligência, ou no caracter, da minima impressão educativa (BARBOSA, 1886, p. VI). ${ }^{2}$

Tanto na Europa, como nos Estados Unidos, se reconheciam as deficiências no aproveitamento das crianças dos anos iniciais de escolarização. Entretanto,

... as críticas à escola vão além do aspecto metodológico. Sua ineficiência é reafirmada imputando-lhe também uma defasagem em relação ao desenvolvimento econômico, que explicaria, inclusive, o alto nível de desempregos e os baixos salários então existentes, uma vez que o trabalho industrial de demanda indivíduos letrados e capazes de raciocinar rápida e criativamente (VALDEMARIN, 1998, p. 67).

Os debates sobre essas questões já se faziam presentes, gerando um movimento de renovação pedagógica a partir de meados do século XIX (VALDEMARIN, 1998). A escola era vista como o ponto central das mudanças sociais relativas à modernização e ao progresso dos países.

Em relação a um novo fazer nas práticas escolares, o ensino intuitivo ganhou adeptos no Brasil. Com primeira edição brasileira em 1886, o livro Primeiras lições de coisas, do norte-americano Norman Allisson Calkins, traduzido por Ruy Barbosa, teve ampla divulgação. O ensino intuitivo fazia coro nas discussões educacionais. Nesse modelo educativo, o ponto de partida é a educação dos sentidos, que tem a finalidade de preparar as

\footnotetext{
${ }^{2}$ Ruy Barbosa faz essa crítica às escolas no prefácio da sua tradução para o português do livro Primary Object Lessons: training the senses and developing the faculties of children; a manual of elementary instruction for parents and teachers, de autoria de Norman Allison Calkins (1822-1885).
} 
crianças para a observação acurada, culminando na construção do conhecimento. Evidenciase nas lições de coisas "o ensino pelo aspecto, pela realidade, pela intuição, pelo exercício reflexivo dos sentidos, pelo cultivo complexo das faculdades de observação" (BARBOSA, 1886, p. vii).

A valorização do ensino de Desenho na Europa, tendo em vista a formação de mão de obra especializada para atender à fundação de indústrias, à crescente mecanização, ao desenvolvimento dos meios e das vias transporte, repercute no Brasil e Ruy Barbosa, em seus pareceres (1883), defende o ensino do Desenho na escola elementar, para crianças partir dos 7 anos, e o Desenho Geométrico, para o Curso Normal. O Desenho é destacado como instrumento educativo, "uma das bases primordiais da cultura escolar e de um dos propulsores mais essenciais ao desenvolvimento econômico..." (BARBOSA, 1883, p. 108) e a "base de toda instrução industrial" (BARBOSA, 1883, p. 179). Nos pareceres, há a proposta do ensino intuitivo, como um princípio geral, ponto de partida de todo o ensino, e a defesa pela renovação do método de ensino nas escolas.

Para fomentar o desenvolvimento da indústria nacional, Ruy Barbosa propunha a inclusão do Desenho nas escolas de forma a contribuir com um contingente de trabalhadores aptos aos ofícios mecânicos e fabris. Verifica-se uma busca pela "modernização educacional no país em relação ao contexto internacional" (SOUZA, 2000, p. 10). O Desenho torna-se a base de todos os trabalhos mecânicos e constitui-se em um saber fundamental para o desenvolvimento da técnica, "os trabalhadores competentes" deveriam "ser excelentes na arte do desenho" (GAMA, 1987, p. 133).

Ruy Barbosa propõe um ensino intuitivo, com utilização de modelos materiais, construções gráficas, reprodução de formas geométricas utilizando papelão, papel, terra plástica ou arame. Após "modelar as combinações geométricas das linhas, superfícies e sólidos", o aluno deveria adquirir "certa preparação elementar no cálculo e medição" das mesmas (BARBOSA, 1896, p. 290).

Esse breve preâmbulo aponta um novo modelo de ensino que veiculava no país e os ideais republicanos que pairavam sobre os legisladores. Tendo como pressuposto básico que, enquanto prática social, o processo educacional deve ser apreendido em seu espaço-tempo dentro de cada contexto histórico, fizemos um estudo sobre o ensino da Geometria e do Desenho na reforma da escola primária promulgada, em 1906, em Minas Gerais.

Colocamos como questão central: como a Geometria e o Desenho estavam prescritos para o ensino primário nas escolas mineiras no início do século XX? Para tentar responder a esta indagação, realizamos uma análise da documentação oficial referente à legislação 
educacional mineira. Apesar de o nosso estudo se focalizar no ensino primário, também faz referências à Geometria e ao Desenho para o ensino normal, já que este era o curso preparatório do corpo docente para atuar naquele nível de ensino.

\section{Alguns aspectos da legislação escolar}

Para situar o ensino em Minas Gerais no início do século XX, devemos retornar ao final do século XIX, para tomarmos conhecimento de reformas que vieram alterar os diversos níveis de instrução no Estado e alguns dados estatísticos.

A legislação escolar da Província de Minas Geraes consultada nos aponta um maior interesse pelo grau de ensino primário a partir de 1870. A Inspetoria Geral de Instrução Pública da Província, em 1886, publicou os dados estatísticos relativos à instrução pública primária, sendo criadas 1527 cadeiras - destas, apenas 336 eram do segundo grau distribuídas da seguinte forma:

Aulas noturnas
Aulas em cadeias
Cidades e vilas
Freguesias
Distritos e povoados

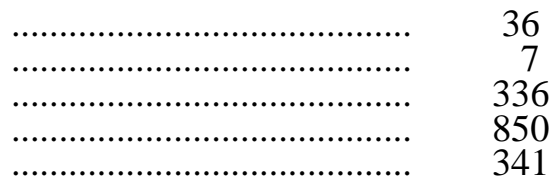

Dentre os dados da Inspetoria, verificou-se que havia 863 cadeiras para o sexo masculino, 601 para o sexo feminino e apenas 63 mistas.

Em 1887, o Presidente Carlos Augusto de Oliveira Figueiredo, em seu relatório, fez uma crítica às escolas normais, afirmando que estas não estavam produzindo o resultado esperado e havia poucos normalistas formados em serviço. Em 1889, também o presidente Barão de Camargos considerava deficiente o resultado das escolas normais. A Inspetoria Geral forneceu dados que demonstravam que o estado tinha um contingente de 43.586 alunos - 15.168 do sexo feminino e 28.418 do sexo masculino. No currículo, já constavam as cadeiras de Geometria e Desenho Linear.

O primeiro ministro da Instrução, Benjamin Constant, através do Decreto $\mathrm{n}^{\circ}$ 981, de 8 de novembro de 1890, criou o Conselho de Instrução Superior e estabeleceu a organização do ensino primário, secundário e normal. As reformas não tiveram êxito, principalmente porque o Ministério da Instrução, Correios e Telégrafos foi extinto em 1892.

O país passou por diversas modificações nos sistemas social, econômico e político, desde os últimos anos do Brasil-Império.

A expansão da lavoura cafeeira, a remodelação material do país (redes telegráficas, instalações portuárias, ferrovias, melhoramentos urbanos, etc.), 
um inicial surto de crescimento industrial e, principalmente, uma urbanização significativa acoplada ao fim do regime de escravidão e a adoção do trabalho assalariado completaram um conjunto de processos e situações que colocavam o país no rumo da modernização (GHIRALDELLI JR., 1994, p. 15).

No contexto mais amplo das transformações que o Brasil atravessou, no final da primeira década do século XX, ocorreu um crescimento industrial e concentração da população em centros urbanos, que suscitaram debates em torno da escolarização da população brasileira. Pouco tempo depois da proclamação da República, ocorrida em 15 de novembro de 1890 , pelo artigo $1^{\circ}$ do Decreto de primeiro de dezembro de 1890 , houve a reformulação da instrução pública mineira e extinção dos externatos. Outros decretos vieram depois deste, entretanto, não tinham como objetivo cuidar do ensino elementar e normal, promovendo reformas nestes níveis de instrução.

O ensino em Minas foi prejudicado com o fechamento dos externatos, já que o número de escolas era insuficiente e também porque, com o novo regime, o estado "não poderia ditar as normas de ensino, reformando as do regime decaído, antes que a situação se normalizasse e que houvesse diretrizes de âmbito federal" (MOURÃO, 1962, p. 18).

Promulgada em 3 de agosto de 1892, a Lei $n^{\circ} 41$, que ficou conhecida como Reforma Afonso Pena, estabelecia que o programa de ensino deveria ser adaptado à região em que a escola estivesse localizada. Nesta época, os programas do ensino primário e normal tinham uma característica enciclopedista.

Pelo artigo 88 da referida lei, haveria um currículo específico para as escolas primárias rurais, distritais e urbanas. Os conteúdos relativos aos saberes matemáticos se restringiam à Aritmética, compreendendo operações com números inteiros e decimais, frações, juros simples e sistema métrico, para as escolas rurais; acrescidos de medidas de área e capacidades, proporções, regra de três e companhia, para as escolas distritais. Nas escolas urbanas, o que diferia no ensino dos saberes matemáticos das outras escolas era a inclusão do cálculo de raízes quadradas e cúbicas. O ensino da Geometria estava completamente ausente nas escolas rurais e distritais, porém, comparecia a indicação de "Noções de geometria" para as escolas urbanas, sem mais referências sobre este ponto específico.

Não se preceituava o ensino de Desenho para as escolas primárias, no entanto, em relação ao Curso Normal, pelo artigo 160 da Lei $n^{\circ}$ 41, prescrevia-se o ensino de "desenho geométrico, topográfico, de ornato, de paisagem e de figura", dentro da cadeira "Geometria e agrimensura", indicando a valorização desses saberes. Haveria uma preocupação em formar os futuros professores com conhecimentos de Desenho para transmiti-los no ensino primário? 
Pelo artigo 167, era estabelecido que o ensino tivesse um caráter prático e profissional e os mestres deveriam se esforçar para que os alunos pudessem adquirir as qualidades intelectuais e morais indispensáveis ao professor primário. O caráter prático do ensino traz, em seu bojo, os princípios do ensino intuitivo.

Em 15 de março de 1895, passou a vigorar o Decreto $\mathrm{n}^{\circ} 814$, regulando o concurso para o provimento das cadeiras de instrução primária. Pelo artigo 39, nas provas, constariam questões práticas de Aritmética e Geometria. O programa do exame incluía tópicos de Aritmética para os cursos rural, distrital e urbano, e, tópicos de Geometria, para os cursos distrital e urbano. Não era mencionado o Desenho.

Na gestão de Chrispim Jacques Bias Fortes, uma nova lei, nº 221, foi promulgada em 14 de setembro de 1897, com disposições relativas às instruções públicas primária e secundária no Estado. Para o ensino primário, as Lições de Coisas constavam como uma disciplina e não havia recomendações para o ensino de Geometria. Relativamente ao Curso Normal, especificava-se que o ensino de Geometria teria por fim a resolução das fórmulas geométricas das linhas, áreas e volumes, durante o $3^{\circ}$ e $4^{\circ}$ anos, sendo suprimidas as noções de agrimensura e não são especificados os desenhos geométrico, topográfico, de ornato, de paisagem e de figura, como estava disposto na lei anterior.

Organizando e estabelecendo novas diretrizes para o ensino público em Minas Gerais, o presidente do Estado, Francisco Silviano de Almeida Brandão, em 16 de setembro de 1899, sancionou a Lei $\mathrm{n}^{\mathrm{o}}$ 281. O Governo reformulava os regulamentos do ensino primário e normal. Com esta lei, haveria uma nova grade curricular para o Curso Normal, sendo excluídas diversas disciplinas que, anteriormente, eram excessivas. Pelo artigo 18, o currículo do Curso Normal teria as seguintes matérias: Português e Literatura Nacional, Francês, Aritmética e Álgebra, Ciências Físicas e Naturais, Geografia e princípios de História Geral e do Brasil, Pedagogia e Aula Prática Mista. Também se incluíam a Geometria e o Desenho. O ensino primário público estadual era gratuito e obrigatório para meninos e meninas de 7 a 13 anos. As escolas foram divididas nas categorias urbanas e distritais, ficando, assim, extintas as escolas rurais. O que se observa, para o Curso Normal, é a valorização do Desenho pela Lei $\mathrm{n}^{\circ}$ 41, de 1892, sua exclusão pela Lei no 221 , de 1897, e sua incorporação pela Lei no 281 , de 1899.

Em 1901, o currículo do ensino normal foi novamente reformulado pela Lei $\mathrm{n}^{\circ} 318$. Entre outras modificações, a cadeira de Geometria e Desenho seria substituída pela cadeira de Geometria Plana e Desenho Linear. 
No início do século XX, um contingente de mais de $80 \%$ da população brasileira era analfabeta (ARANHA, 1996). Pelo quadro geral da educação no país, Minas Gerais, como a província mais populosa, também enfrentava problemas nessa área. Muitas reformas, mudanças a cada governo, tentativas de melhorias na rede de ensino, nos demonstram uma Minas preocupada em ampliar o ensino primário e com a formação de professores para atuar neste nível de instrução.

Em 1906, através do Decreto n 1908, com o presidente Francisco Antônio Salles ${ }^{3}$, a distribuição das cadeiras no Curso Normal foi definida - inclusive unificando o currículo em todas as escolas normais. A Geometria e o Desenho foram dispostos como disciplinas independentes, ensinadas separadamente. Nos quatro anos de curso, havia uma aula por semana de Desenho Linear e, apenas, no $3^{\circ}$ e $4^{\circ}$ anos se estudaria Geometria, com duas aulas semanais.

Tentamos elucidar a falta de esclarecimento, nos regulamentos, do que seria o Desenho Linear. Nos programas do Colégio Pedro II, o Desenho Linear se constituía da construção de figuras geométricas e o Desenho Figurado era baseado em cópias. O autor do livro Elementos de Desenho Linear, Ayres Albuquerque Gama, define Desenho Linear como a arte de representar os objectos, indicando os seus contornos por meio de linhas (GAMA, 1872), sendo o mesmo dividido em Desenho Linear Gráfico (figuras traçadas a mão livre) e Desenho Linear Geométrico, sempre com a utilização de instrumentos como régua, compasso, esquadros. Paulino Martins Pacheco, em seu livro Curso Elementar de Desenho Linear ${ }^{4}$, publicado em 1881, indica que o Desenho Linear, de Ornamento, de Paisagem e o de Figura, seriam os ramos do Desenho e define Desenho Linear como "a representação por meio de linhas e pontos de todos os objectos, especialmente os industraes". Divide o Desenho Linear em "linear à vista" e "linear graphico" - o primeiro, realizado sem o auxílio de instrumentos, com a finalidade de "educar a vista e tornar a mão destra e firme para os trabalhos com o segundo"; o desenho gráfico, "rigoroso e exacto em suas linhas, não póde deixar de ser executado a instrumentos apropriados nem á escala" (PACHECO, 1881, p. 11-12). Teríamos, assim, o Desenho Linear sob duas perspectivas: desenho à mão livre e o desenho com utilização de instrumentos como régua, compasso, esquadros.

\footnotetext{
${ }^{3}$ Francisco Antônio Salles foi presidente do Estado de Minas Gerais no período de 07/09/1902 a 07/09/1906.

${ }^{4}$ O livro Curso Elementar de Desenho Linear, Paulino Martins Pacheco, na edição de 1881, traz na capa a informação de que o mesmo foi aprovado pelo Conselho Diretor da Instrução Pública e adotado pelo Governo nas escolas públicas primárias, secundárias e normais do Rio de Janeiro.
} 
O Desenho Linear Geométrico se fundamenta na teoria da geometria euclidiana plana, sendo o mais valorizado ao longo do século XX, haja vista que foi a modalidade que continuou presente na maioria das escolas que mantiveram a disciplina Desenho (ZUIN, 2001).

Segundo Mourão (1962), o Desenho era "essencialmente o Desenho Linear Geométrico, com suas aplicações, inclusive de ornatos, de perspectiva e de sombras" (p. 90). Com esse formato, entendemos que, no Curso Normal, a Geometria deveria anteceder o Desenho, ou serem cadeiras de um mesmo ano do curso, podendo-se fazer as pontes necessárias entre as construções geométricas e a teoria que as fundamenta, mas não era isso o que acontecia. É importante destacar que esta não era uma realidade apenas em Minas Gerais. O ensino do Desenho se fazia separadamente da teoria da Geometria. Existiam livros didáticos, de autores brasileiros, nos quais as construções geométricas eram apresentadas sem se fazer muitas correlações com a teoria da geometria euclidiana. Em algumas publicações, a teoria estava completamente ausente (ZUIN, 2001).

O Decreto $n^{\circ} 1960$, de 16 de dezembro de $1906,{ }^{5}$ estipulou três anos para o Curso Normal e as matérias que deveriam ser ministradas:

$1^{\circ}$ ano - Português, Aritmética, Desenho, Música e Trabalhos de Agulha.

$2^{\circ}$ ano - Português, Francês, Geometria, Geografia, História, Educação Moral e Cívica, Música, Desenho e Trabalhos de Agulha.

$3^{\circ}$ ano - Noções Gerais de Física, Química, História Natural e Higiene, Aritmética Comercial, Escrituração Mercantil, Música, Desenho e Trabalhos de Agulha. ${ }^{6}$

Pelo artigo 146, se especificava, para o Curso Normal, o ensino de Desenho:

Além do desenho linear mais ou menos completo, o desenho a mão livre, fornecendo-se esclarecimentos e regras para o conhecimento e execução do desenho, educando o gosto artístico e despertando o gênio inventivo. Ideias do claro e escuro e das variedades de desenho artístico, fazendo desenhar ao natural sem imitações servis e dando regras sobre o melhor modo de

\footnotetext{
${ }^{5}$ O regulamento $\mathrm{n}^{\text {o }} 1960$ instaurava a preferência pelas mulheres como professoras para o ensino primário, afirmando que esse era "o meio de abrir á mulher mineira uma carreira digna e proporcionar-lhe ensejo de ser útil á Pátria". A justificativa se pautava no fato de que a mulher "melhor comprehende e cultiva o caracter infantil, e a professora competente é mais apta para a educação sem os desvios do espírito, sem corrupções do coração e sem degradações o caracter". Por outro lado, se acrescentava: "a professora com mais facilidade sujeita-se aos reduzidos vencimentos com que o Estado pôde remunerar o seu professorado". Esses eram os motivos pelos quais se criava, na Capital, uma escola normal destinada exclusivamente ao sexo feminino (MINAS GERAES, 1906a).

${ }^{6}$ Nas escolas normais, as matérias de ensino obedeciam a uma distribuição por cadeiras: $1^{\text {a }}$ cadeira - português e francês; $2^{\mathrm{a}}$ cadeira - aritmética, geometria e escrituração mercantil; $3^{\mathrm{a}}$ cadeira - geografia, história, educação moral e cívica; $4^{\mathrm{a}}$ cadeira - noções gerais de física, química, história natural e higiene; $5^{\mathrm{a}}$ cadeira - música; $6^{\mathrm{a}}$ cadeira - desenho (MINAS GERAES, 1906a).
} 
aproveitar e de dispor a luz. Sombras. Efeitos de luz direta e de luz refletida. Perspectiva. Natureza morta e viva (MINAS GERAES, 1906a).

Se, anteriormente, o Desenho era mais voltado para o desenho linear e geométrico, para se formar professores para o ensino primário e haver uma coerência, percebe-se, pelo Decreto $n^{\circ}$ 1960, a valorização do desenho à mão livre e artístico. Enaltecendo a educação estética, o ensino da música e do desenho deveriam ser dados "com todo o esmero durante todo o curso normal” (MINAS GERAES, 1906a).

A prática do magistério seria realizada nos grupos escolares e nas escolas isoladas sob a direção dos professores da Escola Normal. Outra determinação, fixada pelo artigo 118, era relativa à metodologia:

Não será permittido no ensino normal processo que anime o trabalho machinal e substitua a reflexão por um esforço de memória. Assim o ensino deverá ser feito intuitivamente, por meio de cousas, em todas as matérias em que se puder applicar este processo e principalmente no que diz respeito ao ensino prático (MINAS GERAES, 1906a).

A legislação determinava a aplicação do método intuitivo, inclusive no Curso Normal, buscando uma forma mais efetiva de preparar os futuros professores para desenvolver essa metodologia na escola primária.

\section{Os primeiros grupos escolares mineiros e a reforma de 1906 para o ensino primário}

João Pinheiro da Silva ${ }^{7}$, então presidente do Estado de Minas Gerais, contribuiu com o ensino, através da promulgação da Lei n 439, de 1906, vindo a reformar o ensino primário, normal e superior de Minas.

João Pinheiro e seu Secretário do interior, Dr. Manuel Tomaz de Carvalho Brito, "tiveram a felicidade de introduzir em Minas Gerais, uma modificação realmente substancial no ensino, algo que, então constituía uma conquista dos países mais civilizados do mundo - a instituição dos grupos escolares" (MOURÃO, 1962, p. 93). A criação dos grupos escolares foi uma medida inovadora no país também ocorrendo em outros estados. São Paulo foi pioneiro nesta proposta com a inauguração dos primeiros grupos escolares no país em 1893.

Faria Filho (1996) destaca a importância deste momento histórico, quando a adoção dos grupos escolares vai expressar um rompimento, a "recriação da educação escolar", dentro

\footnotetext{
${ }^{7}$ Silva foi presidente de Minas nos períodos de 11/02 a 23/07/1890 e de 07/09/1906 a 25/10/1908.
} 
de "um movimento de afirmação de uma nova forma escolar, que vinha se dando desde meados do século XIX” (p. 25).

Os grupos escolares representavam

... a ruptura com o passado imperial e com as escolas isoladas (...) a modernização confundia-se com o processo de crescente racionalização da organização do tablado capitalista e com a construção de Belo Horizonte como capital do estado e como cidade projetada racionalmente pelo urbanismo moderno (FARIA FILHO, 2000, p. 23).

Procurava-se uma maior organização do ensino,

... suas metodologias e conteúdos; formar, controlar e fiscalizar a professora, adequar espaços e tempos ao ensino; repensar a relação com as crianças, famílias e com a própria cidade.

(...) moldar as práticas, os ritos, os símbolos escolares, produzindo e expressando, no mesmo movimento, uma nova identidade para os profissionais que se ocupavam da instrução primária.

(...) grupo escolar, como 'instrumento' do progresso e da mudança (FARIA FILHO, 2000, p. 31).

Novas práticas pedagógicas e sociais se fizeram presentes contribuindo para a formação de uma nova cultura escolar. ${ }^{8}$

A reforma de 1906 teve como uma das maiores repercussões a prática de se dividir os alunos em turmas nos grupos escolares, possibilitando que uma professora "pudesse ensinar a grupos de crianças que estivessem em um mesmo ano do curso, criando as condições para o estabelecimento do ensino simultâneo" (FARIA FILHO, 2000, p.152).9

A implantação dos grupos escolares foi uma medida que teve repercussão, devido ao grande contingente escolar que se formava; deste modo, o método simultâneo contribuiu para a "classificação dos alunos em grupos do mesmo grau de adiantamento", sendo possível reunir um número maior de estudantes, "lecionar a muitos, em lugar de lecionar a um só”, o que propiciava a todos “os mesmos estudos, livros e deveres” (MOURÃO, 1959, p. 38).

\footnotetext{
${ }^{8}$ Em uma mensagem, o presidente do Estado de Minas Gerais, João Pinheiro da Silva, revela que, em 1908, estavam funcionando regularmente 22 grupos escolares, totalizando 10.090 alunos. No entanto, das 800.000 crianças em idade escolar no estado, 700.000 estavam fora da escola. Outro dado, 150 alunas se encontravam matriculadas na Escola Normal da capital e a primeira turma se formaria naquele ano.

${ }^{9}$ Faz-se necessário o esclarecimento de dois pontos: $1^{\circ}$ ) A lei $\mathrm{n}^{\circ} 311$, de 8 de abril de 1836 , determinava que, nas escolas elementares do $1^{\circ}$ e $2^{\circ}$ grau de Instrução Pública, se adotasse o método simultâneo "para o ensino da mocidade". O ensino simultâneo, antes da década de 30, no século XIX, se referia ao ensino de leitura e escrita, simultaneamente, e a prática da repetição das lições em uníssono. Depois, passou a se referir a uma prática pedagógica, na qual o professor comandava a atenção simultânea de todos os alunos. $2^{\circ}$ ) Anteriormente, os alunos, em diferentes graus de aprendizagem e idade, eram reunidos em uma mesma turma.
} 
Pelo artigo $2^{\text {o }}$ do Decreto $\mathrm{n}^{\mathrm{o}} 1960,{ }^{10}$ de 16 de dezembro de 1906, o ensino deveria seguir com rigor o método intuitivo e prático, o que demonstra a tentativa dos gestores de garantir um ensino-aprendizagem calcado nas lições de coisas.

Deparamos com reformas substanciais na área da educação em Minas Gerais na primeira década do Novecentos. Pelos documentos analisados, pode-se inferir que havia uma preocupação com o ensino da Geometria e do Desenho no primário. Estes, como saberes escolares valorizados, desde o século XIX, tinham um espaço nas instituições escolares, sendo cadeiras do Curso Normal, como já foi mencionado anteriormente.

Pelo Decreto $\mathrm{n}^{\circ}$ 1947, de 30 de setembro de 1906, foram determinados os programas de instrução elementar, acompanhados das instruções metodológicas e da respectiva distribuição das matérias e do tempo dedicado a cada atividade e matérias, que era igualmente de vinte e cinco minutos em todos os grupos escolares. Estabelecia-se, para a Geometria e Desenho, três aulas semanais para o terceiro ano, às segundas, quartas e sábados, num total de 75 minutos, e, para o quarto ano, as aulas seriam de segunda à sábado, perfazendo um total de duas horas e meia a cada semana, evidenciando a valorização dessa rubrica, com uma maior carga-horária.

A distribuição do tempo para cada matéria, além propiciar uma melhor organização, mostra a preocupação de não se cansar ou entediar as crianças. Aulas de canto e exercícios físicos estavam incluídos entre as atividades diárias.

Em 1906, os grupos escolares iniciavam suas aulas às $10 \mathrm{~h}$ e dividiam as atividades obedecendo a seguinte distribuição: $10 \mathrm{~h}-1^{\mathrm{a}}$ aula; $10 \mathrm{~h} 25 \mathrm{~min}-2^{\mathrm{a}}$ aula; $10 \mathrm{~h} 50 \mathrm{~min}$ - canto; $11 \mathrm{~h}$ $3^{\mathrm{a}}$ aula; $11 \mathrm{~h} 25 \mathrm{~min}-4^{\mathrm{a}}$ aula; $11 \mathrm{~h} 50 \mathrm{~min}-$ exercícios físicos; $12 \mathrm{~h} 15 \mathrm{~min}-5^{\mathrm{a}}$ aula; $12 \mathrm{~h} 40 \mathrm{~min}-6^{\mathrm{a}}$ aula; $13 \mathrm{~h} 05 \mathrm{~min}$ - canto; 13h15min - $7^{\mathrm{a}}$ aula; $14 \mathrm{~h}$ encerramento dos trabalhos escolares (MINAS GERAES, 1906b).

Nas práticas pedagógicas do início do século XX, encontravam-se o método simultâneo e o método intuitivo; ambos repercutiam positivamente, pois

${ }^{10}$ O Decreto n ${ }^{\text {o }}$ 1960/1906 prescrevia que o ensino primário seria ministrado pelo Estado em escolas isoladas e grupos escolares. As primeiras eram classificadas em urbanas, distritais e de colônias - para o sexo masculino, feminino ou mistas. As escolas urbanas eram estabelecidas dentro do perímetro da sede de cidades ou vilas. As escolas distritais eram as localizadas dentro do perímetro da sede dos demais distritos administrativos e, as escolas colônias, eram as que funcionavam dentro das colônias do estado. As escolas rurais poderiam ser instituídas nos centros fabris e manufatureiros que tivessem uma população densa, que tivessem o número de alunos não inferior ao exigido para as escolas em sede no distrito. O governo também se incumbiria de promover, quando possível, as escolas noturnas com a frequência mínima de 30 adultos. O Grupo Escolar se constituiria de tantas escolas quantas fossem necessárias para que todo o curso primário fosse ministrado a cada sexo separadamente (MINAS GERAES, 1906a). 
... o método simultâneo era utilizado para dar uma nova organização à turma, numa negação clara ao método individual. E o método intuitivo foi a forma encontrada para racionalizar o ensino, tornando-o compreensível às crianças e facilitando o trabalho do professor (RESENDE, 2000).

\title{
O ensino de Geometria e Desenho para o primário na reforma de 1906
}

Qual é o elemento-chave que "configura, organiza e ordena" uma disciplina escolar? Antonio Viñao o denomina código-disciplinar, afirmando que

\begin{abstract}
A idéia do código sugere a existência de regras ou pautas, assim como a de sua imposição com caráter geral. Mas também as de estabilidade, consolidação ou sedimentação e coerência interna. Em todo caso, trata-se de um código cujos componentes se transmitem de uma geração a outra, dentro de uma comunidade de "proprietários" do espaço acadêmico reservado, graças aos já resenhados mecanismos de controle da formação da seleção e do trabalho ou tarefa profissional.

Quais são tais componentes? Basicamente três: um corpo de conteúdos (saberes, conhecimentos, destrezas, técnicas, habilidades), um discurso ou argumentos sobre o valor formativo e a utilidade dos mesmos e umas práticas profissionais (VIÑAO FRAGO, 2008, p. 206).
\end{abstract}

A valorização e a legitimação de um determinado saber se centram no códigodisciplinar. O Desenho adquire um maior status, principalmente, a partir da denominada Segunda Revolução Industrial ${ }^{11}$. As construções geométricas se mostram fundamentais em diversas atividades, sendo imprescindíveis para a fabricação de máquinas, no planejamento das novas vias de transporte, entre outros. O Desenho, como pré-requisito fundamental nos trabalhos mecânicos, auxilia o desenvolvimento da técnica, tendo uma valia no campo laboral. As construções com régua e compasso vão estar ligadas à noção de progresso, sendo muito valorizadas.

Em Minas Gerais, o espírito republicano de progresso, a preocupação de se formar os novos cidadãos se faziam presentes e os legisladores estavam conectados às discussões sobre as questões no campo escolar. Dentro deste contexto, a reforma educacional incorpora as ideias que circulavam no final do século XIX e início do século XX.

\footnotetext{
${ }^{11}$ A Revolução Industrial se inicia na Inglaterra, com a industrialização, mecanização do setor têxtil na segunda metade do século XVIII. A máquina de fiar, o tear mecânico, a máquina a vapor foram invenções que impulsionaram o setor industrial e a mecanização alcançou o setor metalúrgico, proporcionando a produção em série. Outros países também passam pelo processo de industrialização. A denominada Segunda Revolução Industrial, na segunda metade do Oitocentos, emerge do contexto da Primeira Revolução Industrial, com novas invenções e desenvolvimentos em algumas áreas. A descoberta da eletricidade, processos para transformar ferro em aço, novos meios de transporte, ampliação das ferrovias, invenção do automóvel e avião, telégrafo, entre outros, acarretaram uma nova dinâmica no campo econômico e social (VICENTINO; DORIGO, 2013).
} 
Em 1906, a legislação escolar, no nível primário, determina, para o $3^{\circ}$ ano, um número de três aulas semanais de Geometria e Desenho Geométrico, enquanto o $4^{\circ}$ ano teria seis aulas semanais. Em relação às escolas singulares - criadas nos locais com um número mínimo de cinquenta menores entre 7 e 14 anos, a critério do governo - estabeleciam-se três aulas semanais de Geometria e Desenho Geométrico, tanto para o $3^{\circ}$ quanto para o $4^{\circ}$ ano.

Mais voltadas para a utilização de objetos concretos, as instruções metodológicas do Decreto $\mathrm{n}^{\circ}$ 1947, de 28 de setembro de 1906, referentes a Geometria e Desenho, eram assim determinadas:

I - Tôdas as noções devem basear-se em coisas concretas, utilizando-se os objetos da classe, do prédio e do pátio para o estado das linhas, dos ângulos, das extensões lineares, quadradas e cúbicas, etc.

II - O desenho tenderá especialmente a habilitar o aluno à reprodução de objetos, a princípio por linhas retas, depois por curvas, aumentado-se gradualmente as dificuldades (MINAS GERAES, 1906b).

Nestas determinações, o Desenho parece manter uma relação com a Geometria. Há a imposição de uma metodologia de ensino e aprendizagem fundamentada em materiais concretos, objetos que estivessem próximos dos alunos, na sala de aula e em outros ambientes da escola, de modo a exemplificar determinados elementos da geometria plana. Estas recomendações, em parte, remetem às orientações contidas nos pareceres de Ruy Barbosa, explicitadas anteriormente.

O programa de Geometria e Desenho para o ensino primário, pelo Decreto n o 1947, de 30 de setembro de 1906, definiu, de forma minuciosa, os conteúdos a serem cumpridos, em cada semestre letivo, sendo apresentados como se segue:

\section{Terceiro ano}

\section{Primeiro semestre}

- Corpo, superfície, face, aresta, vértice.

- Fazer compreender como o ponto produz a linha, esta a superfície, e a superfície o corpo.

- Representação gráfica dêstes elementos, a mão, em diferentes tamanhos e posições distintas.

- Fazer ver como o ponto em movimento produz diferentes espécies de linhas.

- Classificações das linhas. - Posições diversas da linha e sua classificação.

- Corpos, sua forma. - Denominações dos corpos poliedros.

- Formas geométricas derivadas do cubo.

- Esboçar corpos simples em posições distintas e tamanhos diferentes.

\section{Segundo semestre}

- Fazer notar a posição que uma aresta pode tomar em relação a outra.

- Classificar as linhas pelas respectivas posições. Traçá-las

- Traçar retas quebradas e curvas em diferentes posições.

- Ângulos, classificação dos mesmos - observar ângulos nos corpos. 
- Meios vulgares de provar o paralelismo, perpendicularidade e horizontalidade das coisas (sic). Uso do nível de ar e do prumo.

- Meios empregados pelos carpinteiros, jardineiros, etc, para traçarem curvas e retas.

- Régua comum, o compasso e a corda.

- Medição e traçado de linhas sôbre o terreno e sôbre o papel.

- Uso da trena.

- Calcular distâncias a ôlho.

\section{Quarto ano}

Primeiro semestre

- Problemas sôbre traçado das linhas.

- Medição de ângulos.

- Fazer do natural croquis simples, a mão levantada, utilizando-se dos instrumentos.

- Problemas sôbre o traçado e medição dos ângulos.

- Classificação do polígono pelos diferentes modos de encará-lo.

- Área, face, fundo, base e altura.

- Triângulos. - Construir triângulos sobre o terreno. - Problemas.

- Semelhança e simetria de quadriláteros.

- Emprego do quadrado e do quadrilongo nas artes.

- Desenhar objetos comuns.

Segundo semestre

- Construção de quadriláteros. - Combinação destas figuras.

- Áreas dos quadriláteros e do triângulo. - Problemas concretos.

- Desenho de superfícies em posições diferentes.

- Exercícios de inventiva, deixando liberdade e fixando condições dos alunos.

- Construção de polígonos. - Área dos polígonos regulares e irregulares. - Problemas.

- Esboços inventivos combinando polígonos.

- Círculo e circunferência. - Linhas da circunferência e do círculo.

- Problemas.

- Área do círculo; sector, segmento.

- Fórmulas geométricas. - Problemas.

- Cópias de objetos comuns em perspectiva (MINAS GERAES, 1906b).

A proposta toma como ponto de partida elementos da geometria tridimensional para seguir pela geometria plana. Não há uma especificação para os conteúdos que estariam apenas vinculados à Geometria ou ao Desenho; ao que parece, haveria uma intencionalidade de vínculo entre ambos em alguns momentos, estando visivelmente presentes as modalidades de Desenho "linear à vista" e "linear gráfico", este último com uso de instrumentos.

Pelo programa estabelecido para Geometria e Desenho, avaliamos que ambas tinham, em alguns momentos, um caráter prático. Os materiais a serem utilizados eram a régua comum, compasso, corda, trena, prumo, nível de ar. Os alunos deveriam aprender os métodos empregados pelos carpinteiros e jardineiros para traçarem curvas e retas, bem como estimar distâncias, que deveriam ser calculadas "a olho". Alguns pontos remetem às orientações das Lições de Coisas de Calkins, quando este autor indica que o ensino de desenho é "um meio efficaz de habituar a vista à exactidão no comparar, e adestrar a mão em representar os 
objectos" (1886, p. 364). A estimativa estaria presente no terceiro ano e, possivelmente, os alunos teriam mais facilidade de conjecturar sobre as distâncias, pelo fato de o programa de Aritmética para o segundo ano estabelecer atividades com o uso da fita métrica. Essa habilidade seria aprimorada e, no quarto ano, a recomendação era que se fizesse uso da trena. Verifica-se uma conjugação entre os conteúdos de Geometria e medidas. Calkins também aconselha o desenvolvimento do desenho com linhas, ângulos, figuras geométricas e, como foi evidenciado anteriormente, "o ensino pelo aspecto, pela realidade, pela intuição, pelo exercício reflexivo dos sentidos, pelo cultivo complexo das faculdades de observação" (BARBOSA, 1886, p. vii).

A "medição e traçado de linhas sobre o terreno e sobre o papel" e a construção de "triângulos sobre o terreno", sugerem atividades fora da sala de aula, ao ar livre. Percebe-se, nitidamente, uma preocupação em se aliar a teoria à prática, contribuindo para uma aprendizagem mais efetiva e, também, a transformação do espaço escolar: aprende-se dentro e fora da sala de aula; os conhecimentos são apreendidos através dos métodos empregados por carpinteiros, pedreiros, jardineiros e outros profissionais que se utilizam da geometria prática no seu dia a dia.

Outro ponto a ser ressaltado no programa é a criatividade, que deveria ser incentivada. Isto é constatado quando se propõem "exercícios de inventiva, deixando liberdade e fixando condições" e "esboços inventivos combinando polígonos". A recomendação de se realizar atividades empregando-se o quadrado e o quadrilongo (retângulo) nas artes e, também, os exercícios de inventiva, indicam uma preocupação em integrar a Geometria a uma educação artística.

Destacamos as considerações de Faria Filho (2000) em relação às práticas pedagógicas, que se interceptam com a nossa avaliação:

... observa-se que, ao mesmo tempo em que se busca racionalizar a atividade de ensino e, mesmo, em que se afirma a força da racionalidade humana na ordenação do mundo físico e social e do próprio conhecimento, desenvolvese toda uma 'tecnologia' pedagógica cujo objetivo é tornar o aprendizado escolar em algo mais leve, prazeroso e atraente para os alunos (FARIA FILHO, 2000, p. 161).

Reconhecendo a dificuldade no ensino-aprendizagem da Geometria, devido à abstração que, muitas vezes, impossibilitaria ao aluno apreender um conceito ou tratar das questões geométricas, a utilização de material concreto vem ao encontro do método intuitivo, 
pois o mesmo pressupõe uma nova metodologia. A experimentação viria como um procedimento aperfeiçoado da observação.

Para a instrução intuitiva da relação das formas, Johann Heinrich Pestalozzi (17461827) propunha um meio para exercitar a vista da criança em perceber as formas e em determinar as dimensões dos objetos, que a simples intuição lhe fazia conhecer e, para agilizar suas mãos a delinear-las. Pestalozzi, em seu método, focava uma geometria sensível e palpável, que estaria acomodada à capacidade e à compreensão infantil (CHAVANNES, 1807, p. 127-128).

O método intuitivo, preconizado na Europa,

... significou uma tentativa de racionalização do ensino (...) fundamentado na idéia de processos naturais de aprendizagem (...) Chegou ao Brasil no final do século XIX e teve ampla divulgação na Europa na segunda metade daquele século, quando seus defensores acreditaram que sua utilização poderia reverter a ineficiência do ensino escolar. $\mathrm{O}$ ensino deveria partir do particular para o geral, do concreto para o abstrato (RESENDE, 2000).

Do particular para o geral e do concreto para o abstrato, no método intuitivo a aprendizagem do aluno se dá através da observação, acrescida de atividades práticas, da experiência. A presença da professora se faz necessária para conduzir os alunos nas atividades, suscitando indagações que serão respondidas através das observações e conjecturas do aprendiz. O aluno é um agente ativo na produção do conhecimento.

No Nuveau dictionaire de Pedagogie et d'instruction primaire, Buisson coloca que "se a intuição é o meio de conhecimento mais natural dos quais dispomos, é ele dentre todos, que convêm ao ensino, e por excelência ao ensino primário", porém, "o método intuitivo não é um método de todas as idades; é exclusivamente um método para a infância" (BUISSON apud FARIA FILHO, 2000, p. 165).

A intuição, despertada e incentivada nas crianças, levaria à aprendizagem dos conteúdos de uma forma mais efetiva. Percebemos que as atividades propostas para Geometria e Desenho, pelo Programa do Ensino Primário, tinham o objetivo de propiciar a construção de uma representação interna de um determinado problema ou situação, a realização de atividades concretas, direcionando "o desenvolvimento da criança de modo que a observação gere o raciocínio e o trabalho prepare o futuro produtor, tornando indissociáveis pensar e construir" (VALDEMARIN, 1998, p. 69). A busca por selecionar e utilizar 
estratégias diferenciadas proporciona representações e modelos mentais que propiciam uma maior criatividade no tocante à Resolução de Problemas. ${ }^{12}$

A memorização cede lugar às atividades que dão sentido aos conceitos e às teorias da Geometria. A aplicação da teoria na escola abre espaço para sua aplicação na vida prática, podendo ser adequada ao cotidiano de cada um.

No caso do ensino da Geometria e do Desenho para o $3^{\circ}$ e $4^{\circ}$ anos primários, os materiais, régua comum, compasso, corda, trena, prumo, nível de ar, eram imprescindíveis para a fundamentação teórico-prática, dentro do método proposto. A falta desses materiais implicaria em um ensino com os tradicionais métodos de "lousa e giz”, exposição oral, sem correlações com outros tipos de material concreto, cabendo ao aluno copiar a matéria do quadro e decorá-la. Tudo que era recriminado no método intuitivo! Além disso, como vimos, as instruções metodológicas, referentes à Geometria e Desenho, preconizavam a utilização de objetos concretos.

Essas observações são comprovadas por Valdemarin (1998, p. 70-71) ao lembrar que

A adequação do método intuitivo ao campo das ciências naturais é claramente percebida, dado que este conteúdo de ensino pode ser apresentado aos alunos de modo atraente e prático, com a atenção voltada para a compreensão dos usos industriais dos elementos naturais e do trabalho desenvolvido pelo homem para este fim.

A geometria também se presta a inúmeras atividades escolares, todas derivadas de suas aplicações cotidianas...

$[\ldots]$

O desenho, uma das atividades essenciais ao método intuitivo, compreende aplicações artísticas e industriais, possibilitando tanto a ornamentação quanto a construção de objetos. A geometria, sua base indispensável e seu ponto de partida, pode ser desenvolvida a mão livre ou com a utilização de instrumentos e materiais específicos, tais como régua, modelos, papel quadriculado, etc.

Constata-se que o método intuitivo está presente nas instruções metodológicas e na definição dos conteúdos do Programa do ensino primário estabelecidos pelo Decreto $\mathrm{n}^{\circ}$ 1947, de 30 de setembro de 1906.

12 No início do século, as instruções metodológicas para o ensino de Geometria e Desenho, dentro do método intuitivo, vão ao encontro de uma das tendências no ensino-apredizagem de Matemática. "A importância dada à Resolução de Problemas é recente e somente nas últimas décadas [do século XX] é que os educadores matemáticos passaram a aceitar a idéia de que o desenvolvimento da capacidade de se resolver problemas merecia mais atenção. A caracterização de Educação Matemática, em termos de Resolução de Problemas, reflete uma tendência de reação a caracterizações passadas como um conjunto de fatos, domínio de procedimentos algorítmicos ou um conhecimento a ser obtido por rotina ou por exercício mental. Hoje tem a tendência a caracterizar esse trabalho considerando os estudantes como participantes ativos, os problemas como instrumentos precisos e bem definidos e a atividade na resolução de problemas como uma coordenação complexa simultânea de vários níveis de atividade (...) A Resolução de Problemas envolve aplicar a matemática ao mundo real, atender a teoria e a prática ..." (ONUCHIC, 1999, p. 203). 
O Decreto $\mathrm{n}^{\circ}$ 1960, sancionado em dezembro de 1906, indicava que, na medida do possível, em cada grupo escolar, o governo instituiria aulas profissionais sob a denominação de aulas annexas, nas quais os alunos executariam trabalhos práticos apropriados à sua faixa etária, como ofícios de hortelão, arboricultor e jardineiro, noções práticas de construção de habitações e outras. Para o sexo feminino, trabalhos de costura, fabricação de objetos de fantasia e ornamentação. Para essas 'aulas profissionais', o decreto ditava que os estudantes deveriam ser preparados pelos professores no concernente ao desenho linear e à mão livre e no emprego dos métodos usuais aritméticos e geométricos. Nesse aspecto, advém o caráter pragmático do Desenho e dos saberes matemáticos para a formação profissional, de forma integrada.

Outro ponto que fica evidente é relativo à promoção do despertar dos sentidos, de uma educação estética, em que a Geometria e o Desenho, em alguma medida, participariam, desempenhando o seu papel de formar o pretenso cidadão republicano.

\section{Ponderações Finais}

Um olhar para o programa do ensino primário em outros estados, no início do Novecentos, nos aponta situações distintas do que era proposto na legislação para o trabalho com a Geometria e o Desenho neste nível de ensino em Minas Gerais.

No Rio de Janeiro, o Decreto $\mathrm{n}^{\mathrm{o}}$ 844, de 19 de dezembro de 1901, regulava o ensino primário do Distrito Federal e, entre as rubricas, comparecia o ensino de Desenho, estando ausente a Geometria.

Para as escolas primárias do Pará, o Regulamento geral do ensino primário, de 1903, estabelecia o ensino da Geometria, inserindo exercícios de desenho em cadernos, desenho à mão livre, estritamente prático. Fica proposto o estudo de algumas figuras planas, combinações lineares, ornatos, flores, figuras, feitos no caderno e reproduzidos, em maior escala, no quadro na presença do professor.

Ao focar a instrução em São Paulo, pelo Decreto no 1281, de 24 de abril de 1905, o qual aprovou e mandou observar o programa de ensino para as escolas modelo e para os grupos escolares, verificamos que as recomendações situam o ensino de Desenho e Geometria nos quatro anos do primário, porém sem manter correlações entre ambos.

No Rio Grande do Sul, o Decreto $\mathrm{n}^{\circ}$ 874, de 28 de fevereiro de 1906, trazia a recomendação de ser adotado o método intuitivo nas escolas, servindo o livro apenas como 
um auxiliar. Para o ensino elementar, estabelecia-se o ensino do Desenho e não era feita nenhuma menção à Geometria.

Em Santa Catarina, não há a recomendação do ensino de Geometria, nem tão pouco de Desenho, para as escolas primárias, de acordo com o que estava estipulado pelo Decreto $\mathrm{n}^{\circ}$ 348, de 7 de dezembro de 1907.

Para o Espírito Santo, o Decreto n ${ }^{\circ} 118$, de 7 de novembro de 1908, estabeleceu um programa para os grupos escolares e escola modelo anexa à Escola Normal, prescrevendo o ensino de Desenho e Geometria de forma independente. No primário, se iniciava com o desenho do natural, no primeiro ano, dando 'mais ou menos liberdade' aos alunos e propondo desenho original; cópias do natural de objetos simples e folhas, no segundo ano; cópia do natural de flores e frutos, no terceiro ano e, apenas no quarto ano, parecia haver uma ponte com a Geometria, ao se estabelecer cópia do natural com estudo de sombra, animais, plantas, folhas, flores, paisagem etc. e reprodução de grupos de sólidos geométricos. Os conteúdos de Geometria se situavam em elementos da geometria plana e espacial.

O Regulamento Orgânico do Ensino Público do Estado do Paraná, de 15 de outubro de 1909, prescrevia que o ensino nas escolas primárias teria o caráter intuitivo e prático. Estabelecia o ensino de Geometria em consonância com o Desenho, para as quatro séries, de forma gradativa, fixando o programa: noções fundamentais e conhecimento prático das principais formas geométricas, desenho à mão livre, desde o traçado de linhas sem auxílio de instrumentos até o esboço de objetos, seres e pequenas paisagens, desenho geométrico elementar. Para o ensino complementar ${ }^{13}$, noções fundamentais e estudo das principais formas geométricas e desenho geométrico, visando suas aplicações às artes, aos ofícios e às profissões práticas. Para o curso normal, o Desenho Geométrico estaria localizado no $1^{\circ}$ ano e, a Geometria, no $3^{\circ}$ ano.

Entre os sete estados destacados anteriormente, considerando-se cada um dos decretos ou regulamentos analisados, há indícios de que no Pará e, mais nitidamente, no Paraná se decretava o ensino de Geometria e Desenho de forma articulada.

Retomando as prescrições do programa para o ensino primário em Minas Gerais, pelo Decreto $\mathrm{n}^{\circ}$ 1947, de 30 de setembro de 1906, as aulas de Trabalhos Manuais, até o quarto ano, integravam a costura para as meninas. Para os rapazes, até o terceiro ano, os trabalhos manuais teriam por objetivo "habitual-os ao exercicio do trabalho methodico, familiarizando-

\footnotetext{
${ }^{13}$ Pelo artigo 72 e 73, o ensino complementar era dado aos alunos que se habilitassem nas matérias do curso elementar. Tanto o curso complementar, como o elementar, seriam ministrados nos grupos escolares e escolas isoladas do ensino público primário (PARANÁ, 1909).
} 
os ainda com peças e instrumentos de que tenham de fazer uso, no curso de Ensino Technico Primario" (MINAS GERAES, 1906b, p. 10). Verificamos uma consonância entre o ensino de Geometria e Desenho e Trabalhos Manuais. Para este último, no terceiro ano, prescrevia-se, para as meninas, cortar papel formando triângulos, quadriláteros e, papel e papelão para construir caixas retangulares (sic), porta-papel, porta cartas e estojos triangulares (sic). Para os meninos, trabalhos técnicos profissionais.

Sob um olhar atual, no campo da Educação Matemática, os pontos mais relevantes do currículo proposto para o ensino primário mineiro, em 1906, eram:

- aliar a teoria à prática, mostrando que a Geometria está presente em muitas situações do cotidiano;

- relacionar a Geometria às artes;

- incentivar a criatividade, demonstrando uma preocupação com o lúdico na escola;

- relacionar Geometria com medidas;

- construção de um referencial orientando a prática escolar;

- desenvolver a capacidade de estimar distâncias;

- prescrever a matéria Trabalhos Manuais tendo uma intersecção com a Geometria e o Desenho.

Concluímos que o programa de Geometria e Desenho proposto em 1906, para Minas Gerais, e as respectivas instruções metodológicas eram permeadas pelas discussões da época, no campo político, econômico e educacional, constituindo-se em uma preparação para o ensino da Geometria no grau de instrução posterior e visava, também, à formação profissional. Consideramos que a distribuição dos conteúdos, ao longo do ano letivo, teria como objetivo a construção dos conceitos fundamentais da Geometria e a fixação da teoria, através da experimentação e da prática, de acordo com o método intuitivo.

Em 1907, Presidente de Minas Gerais, João Pinheiro da Silva, considerava que a reforma do ensino primário deveria ser completa e total quanto aos métodos de ensino, à disciplina escolar e à fiscalização severa do serviço. Ponderou haver professores que não estavam totalmente preparados para praticar os novos métodos e, para as devidas adequações, um tempo era necessário para que a reforma se processasse de uma forma mais abrangente.

O ensino de Geometria nas escolas tem sido alvo de discussões em todo o mundo, os saberes geométricos têm relevância no currículo escolar, pois

O ponto de partida do processo de construção do conhecimento da criança são as relações que ela estabelece com o mundo que a cerca... A todo momento estamos conhecendo, explorando e posicionando-nos em um 
determinado espaço, dentro de vários pontos referenciais. E é nesta exploração ativa de objetos e dos espaços que se sugere a prática do ensino da Geometria, pois ela fornece elementos para a criança construir as relações espaciais (FONSECA, 1997, p. 35-36).

É importante conhecer e avaliar a proposta de 1906 para o ensino de Geometria e Desenho de Minas Gerais, que apresenta uma proposta que, com as devidas adaptações, pode ser adequada para os dias atuais, auxiliando para uma reelaboração e ressignificação dos conteúdos nos anos iniciais do Ensino Fundamental.

Finalizando, destacamos que os saberes escolares não são neutros, indo ao encontro dos interesses de grupos sociais dominantes. Estão inseridas influências econômicas, sociais, políticas e culturais na seleção - seja ela de conteúdos, de disciplinas ou cultural. Há interesses por trás do que deve ser considerado como conhecimento e, especialmente, definindo o que deve ser o conhecimento escolar. Nas reformas, estão subscritas as tentativas de homogeneizar saberes e práticas pedagógicas. Apesar disto, as escolas não selecionam, da mesma maneira, metodologias e conteúdos a serem desenvolvidos, mesmo que haja um currículo oficial a ser seguido.

\section{Referências}

ARANHA, Maria Lúcia de Arruda. História da educação. 2. ed. ver. e atual. São Paulo: Moderna, 1996.

BARBOSA, Ruy. Preambulo do tradutor. In: CALKINS, Norman Allison. Primeiras lições de coisas. Manual de ensino elementar para uso dos paes e professores. Trad. Ruy Barbosa. Rio de Janeiro: Imprensa Nacional, 1886. p. I-XV.

BARBOSA, Ruy. Reforma do ensino primário e várias instituições complementares da instrução pública (1883). Rio de Janeiro: Ministério da Educação e Saúde, 1947. (Obras Completas, v. 10, t. 2).

CALKINS, Norman Allison. Primeiras lições de coisas. Manual de ensino elementar para uso dos paes e professores. Trad. Ruy Barbosa. Rio de Janeiro: Imprensa Nacional, 1886.

CHAVANNES, Daniel Alexandre. Exposición del método elemental de Henrique Pestalozzi. Trad. Don Eugenio de Luque. Madrid: Imprenta de Goméz Fuentenebro, 1807.

FARIA FILHO, Luciano Mendes. Dos pardieiros aos palácios: forma e cultura escolares em Belo Horizonte (1906-1918). 1996. 362f. Tese (Doutorado em Educação) - Faculdade de Educação, Universidade de São Paulo, São Paulo. 
FARIA FILHO, Luciano Mendes. Dos pardieiros aos palácios: cultura escolar e urbana em Belo Horizonte na Primeira República. Passo Fundo: UPF, 2000.

FONSECA, Solange. Metodologia de ensino de matemática. Belo Horizonte: Lê: Fundação Helena Antipoff, 1997.

GAMA, Ayres de Albuquerque. Elementos de Desenho Linear. Rio de Janeiro: H. Garnier, 1872.

GAMA, Ruy. A tecnologia e o trabalho na história. São Paulo: Nobel/EDUSP, 1987.

ESPÍRITO SANTO. Decreto $\mathrm{n}^{\circ} 118$, de 11 de julho de 1908. Approva o programma de ensino para a Escola Modelo e Grupos Escolares. Diário da Manhã, Victoria. Anno I, n. 263, 19 jul. 1908. p. 1-2.

GHIRALDELLI Jr., Paulo. História da educação. 2. ed. rev. São Paulo: Cortez, 1994.

MINAS GERAES. Mensagem do Presidente do Estado de Minas Geraes, João Pinheiro da Silva. 15 de junho de 1908. Documentos oficiais. Minas Geraes. (Arquivo Público Mineiro).

MINAS GERAES. Decreto no 1960, de 15 de dezembro de 1906. Regulamento da Instrucção primária e normal. Bello Horizonte: Imprensa Official do Estado de Minas Geraes, 1906a.

MINAS GERAES. Decreto $\mathbf{n}^{\mathbf{0}}$ 1947, de 30 de setembro de 1906. Approva o programma do ensino primario. Bello Horizonte: Imprensa Official do Estado de Minas Geraes, 1906b.

MINAS GERAES. Lei $\mathbf{n}^{\mathbf{0}}$ 439, de 28 de setembro de 1906. Auctoriza o governo a reformar o ensino primário, normal e superior do Estado e dá outras providências. Bello Horizonte:

Imprensa Official do Estado de Minas Geraes, 1906c.

MINAS GERAES. Decreto $\mathbf{n}^{\mathbf{0}} \mathbf{1 9 0 8}$, de 28 de maio de 1906. Estabelece a distribuição das matérias do ensino normal pelos quatro annos do curso e uniformiza os programas do mesmo em todas as escolas normaes. Bello Horizonte: Imprensa Official do Estado de Minas Geraes, $1906 \mathrm{~d}$.

MINAS GERAES. Falla que o exm. Sr. Dr. Carlos Augusto de Oliveira Figueiredo dirigio á Assembléa Provincial de Minas Geraes na segunda sessão da vigesima sexta legislatura em 5 de julho de 1887. Ouro Preto: Typographia de J. F. de Paula Castro, 1887.

MINAS GERAES. Documentos oficiais. Seção Provincial. Códice 1386. Minas Geraes. (Arquivo Público Mineiro).

MINAS GERAES. Documentos oficiais. Minas Geraes. (Arquivo Público Mineiro). 
MOURÃO, Paulo Krüger Correa. O ensino em Minas Gerais no tempo do Império. Belo Horizonte: Oficinas Gráficas da Faculdade de Direito da Universidade de Minas Gerais, Centro Regional de Pesquisas Educacionais, 1959.

MOURÃO, Paulo Krüger Correa. O ensino em Minas Gerais no tempo da República. Belo Horizonte: Centro Regional de Pesquisas Educacionais de Minas Gerais, 1962.

ONUCHIC, Lourdes de la Rosa. Ensino-aprendizagem de matemática através da resolução de problemas. In: BICUDO, Maria Aparecida Viggiani. Pesquisa em Educação Matemática: concepções \& perspectivas. São Paulo: UNESP, 1999. p. 199-218.

PACHECO, Paulino Martins. Curso elementar de Desenho Linear. Rio de Janeiro: Imprensa Editorial, 1881.

PARÁ. Decreto no 1190, de 17 de fevereiro de 1903. Regulamento geral do ensino primário. Reorganiza o ensino primário do Estado. Regulamento Geral do Ensino Primário. Disponível em: <https://repositorio.ufsc.br/xmlui/handle/123456789/133719>. Acesso em: 2 nov. 2017.

PARANÁ. Regulamento Orgânico do Ensino Público do Estado do Paraná, de 15 de outubro de 1909. Disponível em: <http://repositorio.ufsc.br/xmlui/handle/123456789/99855>. Acesso em: 29 out. 2017.

RESENDE, Fernanda Mendes. Divulgação e apropriação do método intuitivo em Minas Gerais (Início do século XX). In: CONGRESSO BRASILEIRO DE HISTÓRIA DA EDUCAÇÃO, 1, 2000. Educação no Brasil: História e Historiografia (CD Rom), Rio de Janeiro: UFRJ, 2000.

RIO DE JANEIRO. Decreto nº 844, de 19 de dezembro de 1901. Regula o ensino primário do Distrito Federal. Boletim da Intendencia Municipal, Directoria Geral do Interior e Estatistica, Rio de Janeiro, Typographia da Gazeta de Noticias, Anno XXXIX, out./dez. 1901.

RIO GRANDE DO SUL. Decreto no 874, de 28 de fevereiro de 1906. Reorganisa o serviço da Instrucção publica do Estado. Disponível em: <https://repositorio.ufsc.br/handle/ 123456789/105573>. Acesso em: 29 out. 2017.

SANTA CATHARINA. Decreto no 348, de 7 de dezembro de 1907. Expede Regulamento para a Instrução Pública do Estado. Florianópolis: Typ. Gutenberg, 1908. Disponível em: <https://repositorio.ufsc.br/xmlui/handle/123456789/122161>. Acesso em: 29 out. 2017.

SÃO PAULO. Decreto $\mathbf{n}^{\mathbf{0}} \mathbf{1 2 8 1}$, de 24 de abril de 1905. Approva e manda observar o programma de ensino para as escholas modelo e para os grupos escholares. Assembleia Legislativa do Estado de São Paulo.

SOUZA, Rosa Fátima de. Inovação educacional no século XIX: a construção do currículo da escola primária no Brasil. Cadernos do CEDES, Campinas, n. 51, p. 33-40, nov. 2000. 
VALDEMARIN, Vera Teresa. O método intuitivo: os sentidos como janelas e portas que se abrem para um mundo interpretado. In: SOUZA, Rosa Fátima de; VALDEMARIN, Vera Teresa; ALMEIDA, Jane Soares de. O legado educacional do século XIX. Araraquara: UNESP, 1998. p. 64-105.

VICENTINO, Cláudio; DORIGO, Gianpaolo. História Geral e do Brasil. 2. ed. São Paulo: Scipione, 2013. v. 2.

VIÑAO FRAGO, Antonio. A história das disciplinas escolares. Revista Brasileira de História da Educação. Campinas, n. 18, p. 173-215, set/dez 2008.

ZUIN, Elenice de Souza Lodron. Da régua e do compasso: as construções geométricas como um saber escolar no Brasil. 2001. 211 f. Dissertação (Mestrado em Educação) - Faculdade de Educação, Universidade Federal de Minas Gerais, Belo Horizonte, 2001. 